\title{
AN ANALYSIS OF A SUPERVISOR-SUBORDINATE TRUST RELATIONSHIP
}

\author{
A. S. ENGELBRECHT \\ B. E. CLOETE \\ Department of Industrial Psychology \\ University of Stellenbosch
}

\begin{abstract}
In view of the importance of interpersonal trust as recognized by organizational scholars and the problems associated with the study of trust in organizations, the development of a conceptual model of organizational trust is essential. The aim of this study was to establish empirically the validity of a theoretically sound model of trust in the South African work context. The overall results confirmed a positive relationship between interpersonal trust, trustworthiness and successful trust relationships. The propensity to trust, as well as the length of the supervisorsubordinate relationship, however, did not prove to have a moderating effect on trustworthiness.
\end{abstract}

\section{OPSOMMING}

In die lig van die belangrike rol wat navorsers aan vertroue heg en die probleme verbonde aan die bestudering van vertroue in organisasies, is die ontwikkeling van ' $n$ konseptuele model van organisatoriese vertroue essensieel. Die doel van hierdie studie was om empiries te bepaal of ' $n$ teoreties gefundeerde model van vertroue in die SuidAfrikaanse werkskonteks geldig is. In die algemeen bevestig die resultate die bestaan van in beduidend positiewe verband tussen interpersoonlike vertroue, vertrouenswaardigheid en ' $n$ suksesvolle vertrouensverhouding. Vertrouensgeneigdheid sowel as lengte van toesighouer-ondergeskikte verhouding het egter nie 'n moderende invloed op vertrouenswaardigheid getoon nie.

Recent developments in organizational psychology reflect the need for, and importance of, interpersonal trust relationships in promoting individual welfare and organizational effectiveness (Clark \& Payne, 1997; Kreitner \& Kinicki, 1998). In the current South African context, the issue of mutual trust in working relationships is becoming increasingly vital to business success (Martins, Watkins, Von der Ohe \& De Beer, 1997). The socio-political situation created a social environment characterized by mistrust among the diverse groups in South Africa. Increased work force diversity necessitates that people from very different backgrounds make contact and work together closely. A diverse work force relies with greater difficulty on interpersonal similarity, experience and common background to contribute to mutual attraction and to enhance the willingness to work together. In this regard, the development of mutual trust provides one mechanism for enabling employees to work together more effectively (Mayer et al. 1995). Continuing changes in the workplace towards more participative management styles and the implementation of self-directed work teams, increase the importance of trust, as control mechanisms are reduced and interaction increases.

In spite of the growing importance of trust in organizations, a diminishing level of interpersonal trust is observed in many companies especially between managers and subordinates (Martins et al., 1997; Sitkin \& Roth, 1993). Mutual trust is essential for effective communication between supervisors and their subordinates (Blackburn, 1992). Lack of such mutual trust inevitably results in anxiety, suspicion, uncertainty, low morale, low commitment and low job satisfaction (Mishra \& Morissey, 1990).

Although the importance of interpersonal trust has been acknowledged, little attention has been given in the literature to the systematic and theoretical analysis of how trust develops and functions in organizations. The study of interpersonal trust in organizations has remained problematic, mainly concerning the definition of trust itself; lack of clarity in the relationship between risk and trust; confusion between trust and its antecedents and outcomes; and a failure to consider both the trusting party and the party to be trusted. In order to address these issues, and to clarify the relationship between a specific trustor and trustee, Mayer et al. (1995) proposed a dyadic model of trust in organizations. Form the literature it appears that this model is supported by previous research in the field of in-

Requests for reprints should be addressed to: $A$. S. Engelbrecht, Department of Industrial Psychology, University of Stellenbosch. terpersonal trust (Clark \& Payne, 1997). However, the validity of this model has not been tested empirically, which indicates an important need for further research.

The specific purpose of this study was to test the validity of Mayer et al's (1995) model of organizational trust in the South African context. The present research focussed on analyzing the specific nature of the relationships among interpersonal trust, propensity to trust, the factors of trustworthiness and a successful trust relationship. The general aim was to get a better understanding of the dynamics and performance implications of a supervisor-subordinate trust relationship.

\section{Conceptual model of interpersonal trust}

Although a growing number of researchers in social psycho$\log y$ analyze trust in friendship and family relationships, the nature and basis of trust in such relationships may differ from that in organizations. Mayer et al. (1995) developed a model (see Figure 1) of dyadic trust which focuses on trust in an organizational environment involving two specific parties, namely the trusting party (trustor) and the person to be trusted (trustee). The model includes factors relating to the trustor (propensity to trust) and the trustee (perceived trustworthiness), that were neglected by previous models. They assert that a lack of clear differentiation among factors that contribute to trust, trust itself, and outcomes of trust hindered previous research on trust. According to them all three these facets must be measured in order to test the validity of their model.

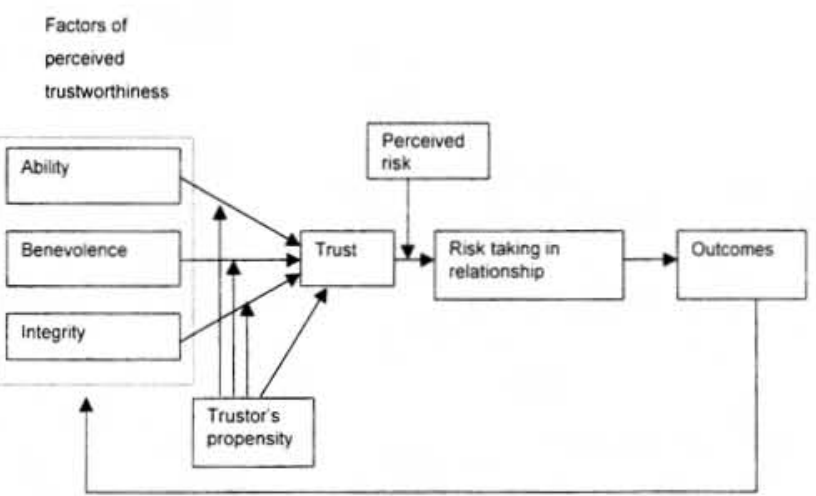

Figure 1: Integrated model of interpersonal trust (Mayer et al., 1995, p. 715) 
Some individuals have a higher general willingness or inherent propensity to trust others. Propensity to trust is proposed to be a stable personality trait that will affect the likelihood that the person will trust others (Clark \& Payne, 1997; Mayer et al., 1995; Rotter, 1967).

Even though propensity would contribute to the explanation of some of the variance in trust, a given trustor exhibits different levels of trust with regard to different trustees. To address this variance, the characteristics of the trustee need to be examined. Although a number of factors that lead to trust have been proposed, three characteristics of a trustee are frequently mentioned in the literature, namely ability, benevolence, and integrity (Butler, 1991; Mayer et al., 1995). Ability refers to a group of skills, competencies and characteristics that enable a person to exert influence within a specific domain (Mayer et al., 1995; Sitkin \& Roth, 1993). Butler (1991), Mishra (1996) and Clark and Payne (1997) refer to a similar construct, namely competence.

Benevolence refers to the extent to which a trustee is believed to act in good faith towards the trustor, without an egocentric profit motive (Mayer et al., 1995). If the trustor perceives that the trustee falls short of any of Butler's (1991) concepts of loyalty, openness, receptivity or availability, it may also decrease the perception of the trustee's benevolence. Similar factors were identified by Mishra (1996) (e.g. openness and caring), and Clark and Payne (1997) (e.g. loyalty and openness).

According to Butler (1991) and Mayer et al. (1995), the implication of integrity for interpersonal trust involves the trustor's perception that the trustee adheres to principles that the trustor finds acceptable. Integrity is characterised by honesty, truthfulness, sincerity and promise fulfilment (Clark and Payne, 1997). Butler's (1991) factors of consistency, discreteness and faimess may also be regarded as facets of integrity.

Each of these three determinants (ability, benevolence and integrity) captures some unique elements of trustworthiness (Mayer et al., 1995). If the trustee is perceived as high on all three factors, the trustee will be perceived as quite trustworthy (Mishra, 1996). Thus, it can be postulated that:

Hypothesis 1: There exist a significantly positive relationship between interpersonal trust and the following factors of trustworthiness:
a) ability
b) benevolence
c) integrity

Gabarro (1978) argues that the research interviews he conducted indicate that, in sequence of importance, integrity, competence and consistency were the most salient conditions of a supervisor's downward trust in a subordinate. Whilst integrity, motives (loyalty/respect) and openness were the most important conditions of a subordinate's upward trust in a supervisor. Butler and Cantrell (1984) tested Gabarro's (1978) rankings of the determinants of trust and listed, from the strongest to the weakest, competence, integrity, consistency, loyalty and openness, for both upward and downward trust. Likewise., Schindler and Thomas (1993) concluded that the relative importance of these five conditions of trust were the same, regardless of the hierarchical relationships between two individuals.

According to Mayer et al. (1995), trustworthiness should be thought of as a continuum along which each of the factors can vary, rather than perceiving the trustee as absolutely trustworthy or not. Ability, benevolence and integrity are important for trust and each may vary independently from the other, although still related. Hence, it can be postulated that:

Hypothesis 2: The factors of trustworthiness influence one another's effect on interpersonal trust reciprocally.

Apart from propensity to trust affecting interpersonal trust when there is no information available on the characteristics of the trustee, propensity can enhance the effect of trust- worthiness, thereby producing a moderating effect on trust (Mayer et al., 1995). Therefore, it can be postulated that:

Hypothesis 3: Propensity to trust has a moderating effect on the relationship between the factors of trustworthiness and interpersonal trust.

The Mayer et al. model (1995) can explain interpersonal trust (based on propensity to trust) before any relationship between two persons has developed. When a relationship begins to develop, the trustor may be able to obtain information on the trustee's characteristics through third-party sources and observation. Integrity, for instance, will be important to the formation of trust early in the relationship, because little in formation is available about the trustee's benevolence toward the trustor. As the relationship develops, interaction with the trustee enables the trustor to gain insight into the trustee's benevolence, and the relative impact of benevolence on trust will grow. The development of the interpersonal relationship is therefore likely to modify the relative importance of the deterrninants of trustworthiness. Consequently, it can be postulated that:

Hypothesis 4: The effect of integrity on interpersonal trust will be most salient early in the supervisor-subordinate relationship, prior to acquiring meaningful information on benevolence.

Hypothesis 5: The effect of perceived benevolence on interpersonal trust will increase as the relationship between supervisors and subordinates develops over time.

According to various researchers (Blackburn, 1992; Butler, 1991; Gabarro, 1978; Kreitner \& Kinicki, 1998), a successful trust relationship can lead to greater co-operation and support of organizational goals, an increase in productivity, the advancement of the developmental potential of subordinates, open communication and honesty.

Mutual trust between supervisors and subordinates is consistent with Graen's (Butler,1991) vertical dyad linkage model. Trust is an essential component in the reciprocal rein forcement in high-quality leader-member exchanges, promoting satisfaction and productivity over time. Transformational leadership is also characterized by mutual trust. According to Bass \& Avolio (1994), a transformational leader supports his/her followers and is trusted and respected by them. A transformational leader becomes effective through empowering his/her followers by giving them autonomy, facilitating their self-development, and serving as a role model of integrity and equity.

Blackburn (1992) conducted a study in South Africa that built on the study of Mishra and Morrissey (1990). Blackburn found that specific forms of behaviour, namely participation in decision making, open and clear communication, honesty, and empathy, had a positive effect on trust in a supervisor-subordinate relationship. The results of Mishra and Morrissey's study supported the main advantages of a successful trust relationship between management and subordinates, namely improved communication, greater predictability, reliability, decreased labour turnover, openness, willingness to accept criticism, and decreased friction among workers. It can therefore be postulated that:

Hypothesis 6: There exist a significant, positive relationship between interpersonal trust and a successful trust relationship.

\section{Sample}

\section{METHOD}

Employees $(\mathrm{N}=131)$ working at various organizations in the Western Cape were selected as sample. Purposive sampling (Kerlinger, 1986) ensured that the sample was representative regarding gender ( $47 \%$ female), age (varied from 18 to 48 years), work experience (varied from one to 31 years), and length of working relationship with supervisor $(50 \%$ more than one year). 
was used to measure propensity to trust. The validity of the Interpersonal Trust Scale has been tested and the results showed acceptable construct and discriminant validity for the scale (Rotter, 1967).

The Conditions of Trust Inventory established by Butler (1991) was used to measure trustworthiness and interpersonal trust. The items for the Conditions of Trust Inventory were selected through a range of confirmatory factor analyses and the factor pattern supported the content and construct validity of the measure (Butler, 1991).

A questionnaire consisting of eight items was developed for measuring a successful trust relationship between a specific subordinate and his/her supervisor. The behaviours identified in the literature as the strongest indication of the outcomes of a successful trust relationship were included as items (Cloete, 1998). A six-point Likert scale was used as a response format.

Both the Interpersonal Trust Scale and the Conditions of Trust Inventory were adapted for the purposes of this study. On the one hand, some items were rewritten to ensure that the meaning was more accurate within the South African cultural context. On the other hand, a six-point Likert scale response format replaced the original five-point scale to counteract the central response tendency (Kerlinger, 1986).

The study found that the adapted Conditions of Trust Inventory ( $\alpha=0.80$ to 0.93 ) and the Successful Trust Relationship Scale $(\alpha=0.95)$ showed high levels of internal consistency, and the adapted Interpersonal Trust Scale $(\alpha=0.76)$ showed a satisfactory level of reliability. The subscale of the adapted Conditions of Trust Inventory used for measuring interpersonal trust produced a high coefficient alpha of 0.93 .

\section{RESULTS}

\section{The relationship between interpersonal trust and the factors of} trustworthiness

The Pearson product-moment correlation coefficients (Kerlinger, 1986) between interpersonal trust and the factors of trustworthiness were determined. High and significant $(p<0.01)$, positive relationships exist between interpersonal trust and each of the factors of trustworthiness (ability: $r=0.77$; benevolence: $r=0.88$; integrity: $r=0.92$ ). Thus, Hypothesis 1 was confirmed.

Standard multiple regression (Tabachnick \& Fidell, 1989) was performed between interpersonal trust as the dependent variable and ability, benevolence and integrity as independent variables, to determine the relative importance of each of the factors of trustworthiness.

Only the regression coefficients of integrity and benevolence differed significantly from zero, with F-values of $70,76(p<0,001)$ and 9,89 (p $<0,05$ ), respectively. Thus, only two of the independent variables contributed significantly to the prediction of the trust a subordinate would have in his/her supervisor, namely benevolence $\left(\mathrm{sr}^{2}=0,01\right)$ and integrity $\left(\mathrm{sr}^{2}=0,08\right)$. Integrity is the most important determinant regarding a subordinate's upward trust in a supervisor, with benevolence in second place. Ability, integrity and benevolence in combination explained $86 \%$ of the variance in trust. Although the correlation between interpersonal trust and ability was 0,77 ( $p<0,01$ ), ability did not contribute significantly to regression. The trust a subordinate has in his/her supervisor can therefore be predicted by only taking into account the scores gained on perceived integrity and benevolence. Apparently the relationship between interpersonal trust and ability is an indirect result of the relationships between benevolence, integrity and trust.

\section{The interrelationship of the factors of trustworthiness}

Hierarchical regression (Tabachnick \& Fidell, 1989) was employed to determine if ability, benevolence and integrity have a mutual effect on each other's effect on interpersonal trust.
Furthermore, the aim was to determine if ability, benevolence and integrity have an additional effect on interpersonal trust besides the interaction-effect of the three factors of trustworthiness on trust.

In step one, the interaction between the three factors of trustworthiness were put in the equation. Secondly, ability, benevolence and integrity were added to the equation in one step. The multiple regression coefficient $(\mathrm{R})$ was significantly $(\mathrm{p}, 0,001)$ different from zero after each step. After step two, with all the variables in the equation, $\mathrm{R}=0,93, \mathrm{~F}(4 ; 126)=198, \mathrm{p}<0,001$.

After step 1, with the interaction-effect between ability, benevolence and integrity in the equation, $\mathrm{R}^{2}=0,78, \mathrm{~F}(1 ; 129)=$ $464,80, p<0,001$. Hence, Hypothesis 2 was supported.

The calculated $\mathrm{F}$-value $(\mathrm{F}=24,48 ; \mathrm{F}(3 ; 126) \approx 3,94, \mathrm{p}, 0,01)$ showed that adding ability, benevolence and integrity to the regression equation led to a significant increase in $R^{2}$. Hierarchical regression showed that the interaction effiect between the factors of trustworthiness explained a significant amount of variance in trust $\left(\mathrm{sr}^{2}=0,78 ; \mathrm{p}<0,001\right)$.

The moderating effect of propensity to trust on the relationship between the factors of trustworthiness and interpersonal trust

The results of the standard multiple regression analysis (Tabachnick \& Fidell, 1989) between interpersonal trust as dependent variable, and ability and ability-propensity to trust interaction as independent variables, showed that the abilitypropensity to trust interaction was superfluous in the relationship between ability and interpersonal trust. Only the regression coefficient of ability differed significantly from zero, $\mathrm{F}$ ( 2 ; $128)=34,34 ; p<0,001$. The ability-propensity to trust interaction did not contribute significantly to the prediction of trust.

Similarly, it was found that the benevolence-propensity to trust interaction and the integrity-propensity to trust interaction did not contribute significantly to the prediction of trust. Consequently, Hypothesis 3 was not supported.

The moderating effect of the length of the supervisor-subordinate working relationship on the relationship between integrity and trust

The aim was to test the proposition that the impact of integrity on trust is moderated by the length of supervisor-subordinate relationship; that is, the longer the working relationship, the lower the impact of integrity. If the length of working relationship (short, medium, long) is represented by two dummy variables (D1 and D2), the research hypothesis implies the following regression model:

$\mathrm{E}\left(\mathrm{Y} / \mathrm{X}_{1} ; \mathrm{D}_{2}\right)=\alpha+\beta_{1} \mathrm{X}_{1}+\beta_{2} \mathrm{D}_{1}+\beta_{3} \mathrm{D}_{2}+\beta_{4} \mathrm{D}_{1}+\beta_{5} \mathrm{D}_{2} \cdot \mathrm{X}_{1}$ where

$E=$ expected value

$\mathrm{X}_{1}=$ integrity

$\mathrm{D}_{1}=$ length of working relationship from medium to long

$\mathrm{D}_{2}=$ length of working relationship from short to long

$\beta_{4} \mathrm{D}_{1} * \mathrm{X}_{1}=$ interaction between $\mathrm{D} 1$ and integrity

$\beta_{5} \mathrm{D}_{2}{ }^{*} \mathrm{X}_{1}=$ interaction between D2 and integrity

By using hierarchical multiple regression analysis, it was found that the adding of $D_{1}, D_{2}, D_{1}{ }^{*} X_{1}$ and $D_{2}{ }^{*} X 1$ in a regression equation in which integrity already appeared, dicl not lead to a significant increase in $\mathrm{R}^{2}$. Thus, it seems as if the length of the working relationship did not moderate the impact of integrity on trust. Hypothesis 4 was therefore not supported.

The moderating effect of the length of the supervisor-subordinate working relationship on the relationship between benevolence and trust

The aim was to test the proposition that the impact of benevolence on trust is moderated by the length of supervisor-subordinate relationship; that is, the longer the working relationship, the stronger the impact of benevolence. The procedure followed for the testing of Hypothesis 5 was the same as for 
Hypothesis 4. It was found that the adding of $D_{1}, D_{2}, D_{1}^{*} X_{1}$ and $D_{2}{ }^{*} X_{1}$ in a regression equation in which benevolence already appeared, did not lead to a significant increase in $\mathrm{R}^{2}$. Hence, it seems as if the length of the working relationship did not moderate the impact of benevolence on trust. Hypothesis 5 was consequently rejected.

\section{The relationship between interpersonal trust and a successful trust relationship}

A high Pearson product-moment correlation coefficient between interpersonal trust and a successful trust relationship was found $(r=0,85 ; p<0,01)$. It appears that a strongly positive relationship exists between interpersonal trust and a successful trust relationship. Accordingly, Hypothesis 6 was supported.

\section{DISCUSSION}

A significantly positive relationship was found between interpersonal trust and the factors of perceived trustworthiness. The results indicate that the trust of a subordinate in his/her supervisor is dependent on the supervisor's trustworthiness as perceived by the subordinate. Given these results, organizations should pay more attention to enhance the ability, benevolence and integrity of employees in their efforts to increase interpersonal trust between employees.

These findings regarding the relationship between interpersonal trust and the factors of trustworthiness were supported by the findings of several researchers (Butler, 1991; Butler \& Cantrell, 1984; Clark \& Payne, 1997; Mishra, 1996). Moreover, these results are in congruence with Mayer et al.s (1995) proposition stemming from their model of interpersonal trust.

It was further found that the sequence of importance of the factors of trustworthiness for the subordinate's upward trust in his/her manager, was integrity and then benevolence. This result regarding the sequence of importance of the factors of trustworthiness is similar to the finding of Gabarro (1978). It, however, differs from the results obtained by Butler and Cantrell (1984), and Schindler and Thomas (1993).

It appears that integrity and benevolence are predominant in determining the manager's trustworthiness as perceived by the subordinate, and that ability does not play a major role. Mayer et al's (1995) model does not specify the sequence of importance of the factors of trustworthiness, although they contend that each of these factors portrays some unique characteristics of trustworthiness. Hence, it seems that the results concerning the role that ability plays in determining the manager's trustworthiness as experienced by the subordinate, is contrary to Mayer et al.'s (1995) contention.

The limitations of significance tests must be kept in mind as a possible explanation of the lack of variance in interpersonal trust through ability. According to Tabachnick and Fidell (1989) ability may appear insignificant because it shares variance with integrity and benevolence, although the three variables in combination are mainly responsible for the size of $\mathrm{R}^{2}$. Because of this, the correlation coefficient between ability and trust must be interpreted additionally to the regression coefficient and the F-value of ability. The significant bivariate correlation, however, can lead to stronger conclusions than is justified if the relationship between ability alone and trust is measured.

Furthermore, it must be kept in mind that this study examined interpersonal trust from one position only, namely from the subordinate upward to the supervisor. Consequently, it is possible that the importance of ability as determinant of trust may increase when trust is examined from the position of the supervisor downward to the subordinate. Then it would be in accordance with Gabarro's (1978) finding that the sequence of importance for a manager's downward trust in a subordinate differs from that for the upward trust of a subordinate in a manager.
It was found that the factors of trustworthiness, namely ability, benevolence and integrity, have a reciprocal effect on each factor's effect on interpersonal trust. These findings suggest that for instance, benevolence alone is not enough to lead to trust if the manager does not display high ability and integrity. These findings are similar to Mishra's (1996) and Mayer et al.s (1995) proposition that ability, integrity and benevolence are related, and that it is possible for a perceived lack of any of the three factors to undermine trust.

Based on the results, it can be concluded that propensity to trust does not have a moderating effect on the relationship between the factors of trustworthiness and interpersonal trust. This finding is in contrast to Mayer et al.'s (1995) assumption in their model of interpersonal trust. Butler (1991), and Clark and Payne (1997), however, found that trust in a specific individual is more relevant in the prediction of work outcomes than the general trust in others (i.e. propensity to trust), which lends some support to the results obtained.

It was found that the length of the supervisor-subordinate relationship, hence the development of the trust relationship over time, did not moderate the relative impact of integrity or benevolence on trust. This finding consequently indicates that the relative impact of integrity and benevolence on trust remain constant as the interpersonal trust relationship between the manager and subordinate develops through interaction over time. This finding is in contrast with the assertion by Mayer et al. (1995) that the effect of perceived integrity on trust will decrease over time, and the effect of perceived benevolence will increase as the trust relationship between supervisors and subordinates develops.

The significantly positive relationship that was found between interpersonal trust and a successful trust relationship was supported by the studies of Cangemi et al. (1989), Mishra and Morrisey (1990), and Blackburn (1992). This finding implies that the outcomes of high interpersonal trust between the subordinate and his/her supervisor can be open communication, empathy, autonomy, cooperation, participatory decision making, fairness, mutual respect, and the creation of opportunities for the utilization of the subordinate's potential.

Since this study regarded interpersonal trust from one position only, it is recommended that future studies should analyze trust from both positions, hence also from the position of the manager downward to the subordinate, to get better insight into the development of mutual trust between the two specific parties.

Further development and operationalization of Mayer et al's model of organizational trust would benefit the study of organizational behaviour and performance. To accomplish a high level of construct validity, new instruments should be developed to measure the perceptions of the factors of trustworthiness, interpersonal trust, and propensity to trust in accordance to the definitions provided by Mayer et al. (1995). Since risk taking is an essential component of organizational trust (Mayer et al., 1995), it should also be accurately measured and included in future validation of the model. In addition to model-specific hypotheses, it is also important to further investigate the process by which trust develops.

In conclusion, it is clear from this study that trust is an essential element of interpersonal relationships and effective management. It is therefore in the interest of organizations to proactively build the level of interpersonal trust between supervisors and subordinates.

\section{REFERENCES}

Bass, B.M., \& Avolio, B.J. (1994). Improving organizational effectiveness through transformational leadership. London: Sage.

Blackburn, D.A. (1992). Trust in manager-subordinate relation- 
ship. Masters Thesis, Johannesburg: University of Witwatersrand.

Butler, J.K. (1991). Toward understanding and measuring conditions of trust. Journal of Management, 17(3), 643-663.

Butler, J.K., \& Cantrell, R.S. (1984). A behavioral decision theory approach to modeling dyadic trust in superiors and subordinates. Psychological Reports, 55, 19-28.

Cangemi, J.P., Rice, J. \& Kowalski, C.J. (1989). The development, decline and renewal of trust in an organization: some observations. Organizational Development Journal, 7(4), 47-53,

Clark, M.C., \& Payne, R.L. (1997). The nature of workers' trust in management. Journal of Organizational Behavior, 18, 205-224.

Cloete, B.E. (1998). An analysis of a successful supervisor-subordinate trusting relationship. Unpublished Masters thesis, University of Stellenbosch.

Gabarro, J.J. (1978). The development of trust, influence and expectations. In A.G. Athos \& J.J. Gabarro (Eds), Interpersonal Behavior (pp. 290-303). New Jersey: Prentice-Hall.

Kerlinger, F.N. (1986). Foundations of Behavioral Research. New York: Holt, Rinehart and Winston.

Kreitner, R., \& Kinicki, A. (1998). Organizational behavior. New York: Irwin.
Martins, N., Watkins, M., Von der Ohe, H., \& De Beer, M. (1997). Trust audit summary report. Pretoria: Centre for Industrial and Organisational Psychology, Unisa.

Mayer, R.C., Davis, J.H., \& Schoorman, F.D. (1995). An integrative model of organizational trust. Academy of Management Review, 20(3), 709-734.

Mishra, A.K. (1996). Organizational responses to crisis - the centrality of trust. In R.M. Kramer \& T. Tyler (Eds.), Trust in organizations (pp. 261-287). Newbury Park: Sage.

Mishra, J., \& Morissey, M.A. (1990). Trust in employee/employer relationships: a survey of West Michigan managers. Public Personnel Management, 19(4), 443-461.

Rotter, J.B. (1967). A new scale for the measurement of interpersonal trust. Journal of Personality, 35, 651-665.

Schindler, P.L., \& Thomas, C.C. (1993). The structure of interpersonal trust in the workplace. Psychological Reports, 73, 563-573.

Sitkin, S.B., \& Roth, N.L. (1993). Explaining the limited effectiveness of legalistic remedies for trust/mistrust. Organizational Science, 4(3), 367-392.

Tabachnick, B.G., \& Fidell, L.S. (1989). Using multivariate statistics (2nd ed.). New York: Harper Collins Publishers. 